\title{
Processos de criação na atenção e na educação em saúde. Um exercício de "timpanização"
}

\section{| ${ }^{1}$ Emília Carvalho Leitão Biato, ${ }^{2}$ Ricardo Burg Ceccim, ${ }^{3}$ Silas Borges Monteiro |}

Resumo: O estudo propõe reflexões que tangenciam as práticas de atenção e educação em saúde. Essas práticas, em muitos aspectos, são permeadas por uma base dualista, que enfraquece a potência educativa e a efetividade na promoção da saúde. Aposta-se na possibilidade de que o gesto de timpanizar, proposto por Jacques Derrida, oferece uma possibilidade de aproximação metodológica com o tema, exercício que é feito a partir da leitura de textos produzidos por estudantes de Medicina no contexto de uma aula e de uma carta escrita por Antonin Artaud, considerando sua biografia e suas vivências de saúde-doença. Timpanizar inclui três procedimentos: tatear escombros, disseminar sentidos e criar cadeias de suplementos. Este método cria possibilidades de novos sentidos para conhecimentos e práticas de atenção e educação em saúde.

> Palavras-chave: filosofia; método; educação em saúde; tríade saúde-filosofia-educação; ensinar saúde.

\author{
1 Departamento de \\ Odontologia, Universidade \\ de Brasília. Brasília-DF, Brasil \\ (emiliacbiato@yahoo.com.br). \\ 2 Programa de Pós-Graduação \\ em Educação, Universidade \\ Federal do Rio Grande do \\ Sul. Porto Alegre-RS, Brasil \\ (burgceccim@gmail.com).

\footnotetext{
${ }^{3}$ Departamento de Teoria e Fundamentos da Educação, Universidade Federal de Mato Grosso. Cuiabá-MT, Brasil (silasmonteiro@me.com).
}

Recebido em: 27/09/2016 Aprovado em: 30/04/2017 
Com a premissa de que a efetividade dos processos de atenção e educação na saúde inclui, necessariamente, a participação de quem é atendido, considerase que movimentos como passar a palavra e criar parcerias na produção de conhecimentos e práticas saudáveis são inerentes ao agir em saúde. OnockoCampos e Campos (2006, p. 669) afirmam que "além de produzir saúde também caberia ao sistema de saúde contribuir para a ampliação do grau de autonomia das pessoas", no sentido de permitir a liberdade e a participação na reorientação dos serviços de saúde, na criação de espaços comunitários saudáveis, no diálogo com a equipe de saúde e com as instâncias gestoras.

Há diferentes modos de se envolver, permitir e provocar a participação, que estão ligados ao modo como se efetivam as práticas de saúde e educação na saúde. Quando o profissional e a sociedade agem no sentido de normatizar a vida do outro, sem oferecer possibilidades de escolher, predomina uma condução moralizante e de controle de comportamentos e estilos de vida. Essa conduta puramente prescritiva, com fechamento às possibilidades de criação de modos de viver, parece estar vinculada a uma visão dualista dos processos de saúde e doença, com ações fundamentadas em critérios rígidos, como: bem x mal, saudável $\mathrm{x}$ doente, condutas certas $\mathrm{x}$ condutas de risco.

Essa base em dois - como a questão shakespeariana "ser ou não ser" polariza os estados de vida, cria estereótipos, estigmatiza e limita o processo de ensino e aprendizado ao saber $\mathrm{x}$ não saber, dentro $\mathrm{x}$ fora, o educador que sabe $\mathrm{x}$ o educando que não sabe. Com base dualista, muitas medidas de Saúde Coletiva desvalorizam o saber popular - dos usuários e comunidades - e perdem potência educativa e efetividade na promoção da saúde; ainda com a rigidez de conteúdos certos e errados, o saber científico limita a participação de estudantes da Saúde, desvanecendo a autonomia e o potencial criador de práticas inovadoras e pertinentes ao funcionamento do nosso sistema de saúde. Nesse contexto, como pensar em processos criadores no campo da Saúde? Como notar e atuar nas práticas de atenção, em bases que não simplifiquem as dinâmicas de viver, adoecer e morrer? Há linhas de fuga aos fundamentos científicos que se fizeram dogmáticos?

Há uma importância em se retomar criticamente o tema, o que é feito aqui a partir de um olhar para a interface da Saúde com a Filosofia e a Educação, com reflexões que tangenciam tanto as práticas de atenção e educação realizadas 
por profissionais em direção aos usuários dos serviços, quanto os percursos formativos em saúde.

Entende-se que a Filosofia é um campo clássico que, desde a Antiguidade, apresenta vínculo com as Ciências Médicas, operando com "mutualidade operativa e conceitual, intercambiando conceitos e métodos como processos culturais da educação, ou, como dito pelos gregos, da formação” (MONTEIRO et al., 2012, p. 301).

Opta-se, neste estudo, por lançar mão da tríade Saúde-Filosofia-Educação pelo viés de uma leitura da filosofia do francês Jacques Derrida, que faz operar a radicalidade da morte da metafísica — e, por conseguinte, da morte dos dualismos - proposta por Friedrich Nietzsche. Assim, propóe-se um deslocamento, um exercício de pensamento, deixando a tradição ocidental dualista, em opção por um percurso que quer ampliar perspectivas acerca da atenção e da educação na saúde, com vistas a problematizar as formas de atuação nesses campos.

A ideia derridiana de timpanizar (1991) a filosofia implica o rompimento da membrana que estabelece espaços nitidamente definidos — o dentro e o fora para operar o pensamento de forma não binária, permitindo extravasamentos. Aborda-se, aqui, a hipótese de que esse gesto de timpanização se configura como um caminho à reflexão sobre práticas de atenção e educação na saúde. Diz respeito aos encontros vivenciados por educador/docente ou ao profissional da atenção, quando em processos formativos ou autorreferidos, também ao usuário, sob certas condições de contato com as ações e serviços de saúde (educação e promoção da saúde, projeto terapêutico participativo, clínica da narrativa).

O texto, portanto, propõe uma aproximação ao timpanizar, que, articulado a outros elementos do pensamento de Derrida, apresenta-se aqui como um método - a descrição de um percurso de realização de procedimentos que provocam o pensamento. Este método se constitui de três gestos indissociados - tatear escombros, disseminar sentidos e criar cadeias de suplementos. Estes gestos são aqui descritos e problematizados com a leitura de trechos de textos produzidos por estudantes durante uma aula no curso de Medicina, em articulação com a leitura de uma carta escrita pelo teatrólogo francês Antonin Artaud, considerando, ainda, sua biografia e suas vivências de saúde-doença no contexto das ações em um serviço de saúde. Pretende-se, assim, criar nexos entre essas diferentes perspectivas/experiências acerca dos processos de saúde-educação. 


\section{Da desconstrução derridiana à proposição de um método}

Tomar a desconstrução derridiana (CAPUTO, 2002) por elemento fundamental para a proposição de um método exige a compreensão da noção de método "do grego, méthodos: em meio a" (MONTEIRO e BIATO, 2008, p. 256) como caminho; e este como instância labiríntica, pouco previsível, provocadora de movimento, e de cartografia imprecisa.

Nesse sentido, Dagmar Meyer e Marlucy Paraíso (2012) organizaram textos que apontam para percursos de estudo com base em teorias pós-críticas, de influências nietzschianas, pós-estruturalistas, de caráter multicultural, entre outros. Tomando essas matrizes de pensamento, questiona-se: "que modos de fazer pesquisa são esses que compartilhamos quando assumimos perspectivas pós-estruturalistas de investigação... nas áreas da educação e da saúde?” (p. 49). As autoras destacam o quanto as questôes metodológicas nessas áreas mobilizam o pensamento e demandam esforços "de invenção e ressignificação" (p. 23). Assim sendo, e por compreender que tanto o objeto quanto as abordagens desejadas encontram-se nesse contexto descrito pelas autoras, propõe-se a apresentação e o exercício de procedimentos que, juntos, compõem aportes metodológicos correspondentes ao referencial teórico escolhido.

O que um método pode estabelecer são modos de fazer, angulações, perspectivas com que se vai investigar e interpretar e apresentar desafios de exposição, experimentação e "laboratório" com o tema: fornece as perguntas, as necessidades de conhecimento aprofundado. Pelo menos, com este texto, desejase apresentar um método direcionado aos objetos inscritos no campo da Saúde e da Educação em Saúde, em que cabem posições entendidas como marginais, por ser a saúde composta por elementos instáveis, de limites imprecisos, que estão sempre em jogo. Esses objetos, frequentemente, acabam por ser envolvidos em uma lógica clássica dualista, e julga-se que este modelo analítico simplifica a complexidade e a diversidade do campo. Nesse contexto, ensaia-se o método de timpanização, proposto a partir da leitura do pensamento de Derrida, à medida que toma seus pressupostos para, então, inventar caminhos, modos de interrogar, procedimentos gestuais que permitam dizer das práticas.

Conforme Peeters (2013), ao olhar de frente para as estruturas filosóficas que "encerram o logos, a razão, numa espécie de fechamento" (p. 228), Derrida se põe a romper com a clausura e consegue realizar um movimento positivo de geração 
e provocação de novas bases para o pensamento. A desconstrução, segundo Niall

Lucy (2004), não pode ser entendida como um movimento de oposição ao que existe previamente, nem simplesmente como uma crítica, um discurso, uma operação. Isso em função da dificuldade em estabelecer a afirmação de que a desconstrução é alguma coisa. Não é possível conjugar o verbo ser para dizer sobre a desconstrução, uma vez que sua primeira contribuição se apresenta, justamente, como a negação da autoridade do é, do verbo ser conjugado no presente do indicativo: "se as coisas são desconstruíveis, elas já o eram - como coisas" (p. 11).

Questiona-se, portanto, o quê das identidades endurecidas dos conceitos e das ações em saúde são desconstruíveis e como podemos tateá-las. Deseja-se a 'coisa mesma’ em ações de saúde e educação na saúde: promove-se uma saúde como quem trata uma entidade; trata-se do adoecimento, considerando-se a essência e a entidade do 'ser doente'; operam-se movimentos de curar, com a pretensão de alcançar respostas orgânicas completas e de retorno a um estágio de sanidade anteriormente experimentado; procura-se a definição precisa do que se considera normal; busca-se a fórmula para ensinar e aprender em Saúde — para formar bem o profissional, no caso do estudante; para conseguir a adesão à terapêutica proposta ou o controle de comportamentos de risco à saúde, no caso de pessoas atendidas.

A proposta derridiana provoca a compreensão de que a 'coisa mesma' essência - se furta ao jogo de significantes, de modo que se permanece aspirando ao impossível, quando se espera acessar algo que se encontra desconstruído.

Também se torna impossível dizer que a desconstrução é a não essencialidade, pois até esta negação já seria um movimento para sua definição. Destarte, o pensamento desconstrutivo de Derrida parece se aproximar dos acontecimentos, de eventos que não esperam deliberação nem consciência (LUCY, 2004). É ação de tatear escombros, e escombros não são organizados. De acordo com Santiago (1976), para que se realize uma leitura da desconstrução, é preciso assumir "o fechamento da metafísica ocidental" (p. 17), colocando-a no campo dos pensamentos em estado de esgotamento quanto ao que se precisa pensar e diante do modo como se deseja pensar. No entanto, para que seja possível "encetar" a desconstrução (DERRIDA, 2001, p. 123), é preciso haver uma nutrição com as forças encontradas no discurso a ser desconstruído. O objeto da desconstrução a busca pela essência das coisas e o raciocínio dualista — serve de substrato, como escombro. Timpanizar a Filosofia funciona como um gesto de desconstrução. 
O tímpano, na história da verdade, é tecido esticado para a tipografia, funcionando como "tela estendida, orlada, encaixilhada, vigiando suas margens como um espaço virgem, homogêneo...” (DERRIDA, 1991, p. 29). No entanto, a história da verdade omite a ocorrência de um tímpano se fender, deixar vazar ou se enxertar. Timpanizar implica romper com a vontade de verdade - de acessar o mundo das ideias platônico (MOREIRA, 2007)—, implica colocar-se às margens, movimentar o pensamento e descrevê-lo em bases novas: filosofar com um martelo.

O martelo, por um lado, dá as pancadas no tímpano, como o batuque num tambor - e não é à toa que o verbete "membrana timpânica" no Dictionary of Health Education (BEDWORTH e BEDWORTH, 2009) traz o termo "ear drum", como drums: tambores. Por outro lado, o martelo é órgão que amortece as vibrações e evita que o tímpano sofra as dores da violência das vibraçôes sonoras. De caráter duplo, as marteladas rasgam e amortecem a membrana. A timpanização é recital de batuques (BIATO e MONTEIRO, 2016, p. 182).

Nesse sentido, ao se proceder à timpanização, estabelece-se um trabalho de observação e interpretação, tomadas não em desvelamentos, mas em atuação e performance, conforme percebemos com Nietzsche: "com os gregos nós podemos aprender o que experimentamos em nós mesmos", sucede que "interpretam-nos nossas vivências" (NIETZSCHE 2012, s/p). O trecho do fragmento póstumo de 1871 se localiza no primeiro período nietzschiano, que vai de 1870 a 1876 . A obra de Nietzsche, nesse momento, tem influência da filosofia de Schopenhauer e das obras de Wagner e, encantado pela tragédia grega, toma o coro helênico: "salva-o a arte, e, pela arte, salva-o para si a vida" (MARTON, 2013, s/p), e afirma as vivências como próprias da ordem do corpo e de suas sensaçôes. Parece, então, ser possível acolher a interpretação, a partir das ênfases que se encontram no primeiro período da obra nietzschiana, como atuação, como performance, numa imagem do ator em cena.

Quando trata do teatro, Nietzsche se refere à tragédia grega. Toma-a como expressão, na cena, de um modo de perceber e conceber a vida: a teatralização da sensação de perda, impacto do que sempre escapa, como a imagem do gênio helênico. Começa, assim, a destacar o desgaste do conceito de verdade, e a tratálo como móvel, provisório e instável. Da perspectiva da tragédia, a vida é livre de fixaçōes e alheia ao sentimento de posse: "no vir a ser tudo é oco, enganoso, raso" (MARTON, 2013, s/p). Interpretam-nos as nossas vivências, conforme atuem artisticamente, fabulando as formas de vida, como vetores livres no chão do 
tablado. A vida é aproximada da ficção, e as práticas biográficas são colocadas "ao lado da fabulação" (COSTA, 2010, p. 31), como ocupantes do mesmo território e, assim, expostas ao mútuo contágio. Viver e inventar deslizam em interpenetrações, de modo que se torna impossível a distinção dos limites de uma e outra ação.

Estamos sujeitos às nossas fraudulentas sensações, e isso é o que há. Com destaque em itálico, indicando um termo usado de modo satírico, quando com sentido diverso ao comumente usado, Nietzsche constata: "não há trilhas ou atalhos para o mundo real!” (NIETZSCHE, 2004a, \$117, p. 234). Não havendo via para o real, em uma aproximação da verdade como invenção, achega-se à noção de simulacro, conforme discutido por Jacques Derrida (2009a). Em sua leitura do Ecce homo de Nietzsche, o filósofo francês destaca seus nomes plurais, as máscaras e pseudônimos com os quais assina seus escritos. Toda assinatura parece constituir uma máscara; mesmo que várias máscaras sejam retiradas em sequência, o que se encontra é sempre o simulacro.

Derrida (2009a) parece desobrigar-se da decisão hermenêutica e exegética do texto, quando afirma que a interpretação na leitura e na escritura é gesto de "intervenção performática” (p. 76). Nesse sentido, as verdades são acontecimentos; e pouco importa se esta atuação-interpretação seja sempre uma falsificação (LÉBRUN, 1983). Em Fragmentos do espólio, Nietzsche (2004b) afirma que cada ação carece de uma interpretação, ao que ele mesmo oferece novas palavras e novas maneiras de decifrar enigmas.

No lugar de tentar decifrar cada ação, cada palavra, nós as interpretamos como quem reconhece o caráter fabulatório desse gesto. Sem desconhecer que estamos lidando com a ficção, e com a impossibilidade de apaziguar o jogo de forças e as multiplicidades que habitam o texto, os corpos e as situações, pomonos a interpretar — num jogo performático — com nossas vivências.

Num ensaio de tomar as práticas de atenção e educação em saúde pela via da timpanização, realizou-se a leitura de uma carta escrita pelo teatrólogo francês Antonin Artaud durante o período em que esteve internado em manicômios (MÈREDIEU, 2011), por entender que nessa carta há traços de vivências de saúde-doença-atenção.

Para além dessa carta de Artaud, e em busca de entrelaçamentos com ela, lançou-se mão de trechos de textos de estudantes do curso de Medicina, produzidos durante uma aula que tratava da Ciência e da influência de suas concepções - 
por vezes, dogmáticas — no movimento profissional de atender e educar em saúde. Para a construção desses dados, o projeto de investigação respeitou os procedimentos normativos e de aprovação em Comitê de Ética em Pesquisa.

A aula na qual os alunos escreveram os textos selecionados neste estudo teve, por objeto, o debate acerca de Ciência e Verdade, com foco nas Ciências Médicas. Tomou, como referências, textos de autores como Sigerist (2011), Porter (2008), bem como considerações nietzschianas acerca de verdade e realidade (2001). Para além da exposição dialogada, os alunos discutiram em grupos um trecho de Azeredo (2012) sobre a interpretação e observaram os quadros Lição de anatomia do Dr. Tulp (Rembrandt, 1632) e O espelho (Picasso, 1932). Nesse contexto, o professor solicitou que os estudantes escrevessem, individualmente, um pequeno texto, contendo as principais impressôes acerca da aula do dia. Levanta-se a hipótese de que a tomada do texto de Artaud permite uma aproximação com a voz de um paciente, enquanto a escritura dos estudantes oferece pistas acerca das características da formação e da atuação em Saúde.

No recorte deste estudo, uma carta de Artaud e dois trechos de estudantes foram selecionados e utilizou-se o método de timpanização, conforme apresentado a seguir - cada procedimento foi descrito e, simultaneamente, foram ensaiados seus modos de usar.

\title{
O método de timpanização e seus três procedimentos
}

\author{
A Jean Paulhan \\ Rodez, 21 de outubro de 1945.
}

Meu querido amigo,

...eu me lembro de que um dia em Paris em 1937 maldisse sua consciência porque o homem que é você se negava a ajudar-me no plano do real absoluto que é no qual nos encontramos todos, plano do retrátil fustigante do ser, que em sua retração toma algo com que fustigar um pouco mais o corpo, derramando sobre ele as trevas da covardia... (ARTAUD, 1986, p. 128).

Precisamos, no decorrer da história, criar métodos rígidos e complexos de conduzir experimentos científicos... porém, há muito mais no mundo, na vida e na morte do que o certo e o errado, o bem e o mal (Estudante A).

Muitas vezes, na área médica, não paramos para pensar sobre os fatores envolvidos no encontro com o paciente... devemos ser mais críticos ao tratarmos uma verdade... e respeitar as verdades do paciente (Estudante $\mathrm{B})$. 


\section{Tatear escombros}

Tatear escombros é gesto de experimentação de sentidos e conceitos, a partir dos cruzamentos da desconstrução com a ficção. É, em rompimento com a busca por verdades absolutas, assumir o simulacro e a transgressão no movimento de observar e lidar com os acontecimentos, de modo a inventá-los, recriá-los, experimentando outras perspectivas.

Ao tomar a desconstrução como "um instrumento conceitual", e não como "palavra mestra” (PEETERS, 2013, p. 544), entende-se que há um funcionamento que possibilita que as noções que permeiam práticas de atenção e educação na saúde se tornarem outras, não que sejam exatamente novas: os mesmos termos, tomados em meio a um movimento que já lhes acomete. É a desconstrução de seu caráter dualista — que permite passar a entendê-las sem princípio, sem verdade, sem essência - que se deseja tatear.

O que se espera desse 'tatear' é que sejam percebidos os jogos de forças, sem tentar encerrá-los e solucioná-los: que, de algum modo, o enigma seja sublinhado (BARTHES, 2005) e não exatamente desvendado. O tatear não é busca por decifração das verdades, é, antes, uma possibilidade analítica de consolidação de um jogo capaz de tragar as estruturas ontológicas da metafísica. Tateando escombros da escrita de Antonin Artaud, a carta enviada a Jean Paulhan foi escolhida entre outras que vieram de dentro de um manicômio em Rodez. Escrita com sangue. Artaud carregava intensamente sua loucura e sua arte como faces da mesma moeda. Se a tradição dualista encerra a loucura como entidade completa e complexa que habita um corpo, o "tatear" permite ver que a loucura e a arte em suas incompletudes tecem o estilo artaudiano, sem precedentes absolutos — nem todo louco é artista nem todo artista é louco - e sem generalizações.

Nessa perspectiva, uma aula sobre Ciências Médicas pode permitir que os estudantes sejam protagonistas na crítica e autocrítica a respeito de dogmas aprendidos e reproduzidos. O que se mostra contundente, nos dois exemplos, é que a saúde e a doença podem ser percebidas como habitantes do mesmo corpo, ou melhor: o corpo, em seus processos de vir a ser, cria seus estilos, incluindo, simultaneamente, saúde e doença.

Artaud foi internado em diversos asilos franceses, com ideias delirantes. Possivelmente, em seu prontuário clínico, psiquiátrico e psicológico, ler-se-iam "carência do ser e pensamento separado da vida" (DERRIDA, 2009a, p. 252). 
Faltaria, a essa vida, o encaixe em padrões de normalidade. Porém, precisamente suas condições clínicas e poéticas compõem Artaud, com sua enorme capacidade de despregar-se, de não pensar linearmente, e provocam a criação de um teatro com nova feição.

O motivo que levaria os críticos a abandonarem o pensamento de Artaud aos médicos e psicólogos é tomado por Derrida como fascinante. Nesse sentido, citando Michel Foucault, ele afirma que "a aproximação que estabelecemos entre a evolução da esquizofrenia e a da obra, leva a conclusões que de modo algum podem ser generalizadas" (DERRIDA, 2009a, p. 255). Por mais que o clínico reconheça a provável genialidade do esquizofrênico e até mesmo procure por ela como um dos sintomas da esquizofrenia, não é disso que se trata. Em Artaud, a cumplicidade entre a potência de criação e a loucura parece ser única, ambígua, poética. Se o entendemos, "não devemos esperar dele uma lição" (p. 256), já que "o que ele diz é uma intensidade que não poderíamos suportar", conforme afirma Mallarmé (apud DERRIDA, 2009a, p. 253).

Assim, o procedimento de tatear escombros destaca o caráter dogmático e dualista dos diagnósticos e terapêuticas, que se pautam em verdades absolutas: as características esperadas de um esquizofrênico e a conduta de isolamento preconizada na época. Aqui, o tatear chama à reflexão sobre algumas práticas de atenção e educação na saúde que permanecem dicotomizadas e firmadas em absolutos.

Tomando, como exemplo, a Educação Permanente em Saúde (EPS) como política, mas também como viés pedagógico — , nota-se esse necessário rompimento (desconstrução) com a lógica dualista que divide aspectos teóricos e práticos e endurece as respectivas verdades e funções. Dos escombros rígidos de um e outro, parece ser possível fazer algumas aproximações no sentido de compreender a indissociabilidade de teoria e prática, como um duplo gesto. Ao se considerar a EPS como "uma estética pedagógica para a experiência da problematização e da invenção de problemas” (CECCIM, 2005, p. 175), entende-se que a experiência em território tem potencial de fomentar a criação inventiva de problemas e modos de lidar com eles. Para tanto, propõe-se reconhecer os escombros — os rastros do raciocínio binário —, manipulá-los, usá-los por substrato de modo crítico, na pretensão de novos modos de fazer, com flexibilidade e potência de criação, conforme se apresenta no segundo gesto. 


\section{Disseminar sentidos}

Disseminar é um gesto que declara uma linguagem de fuga às familiaridades e às representações. Sem pretender achar os significados originários perdidos sobre saúde-doença, educação e atenção nos textos, nos movimentos, nas expressões da vida, exerce-se o gesto de disseminar sentidos, à semelhança de uma multiplicação em processos acelerados de mitoses, porém, sem fidelidade ao teor de DNA. Para Dominique de Villepin (PEETERS, 2013), a leitura desconstrutora tem caráter criador e libertador, como força de desfazer sem destruir, e seguir adiante.

$\mathrm{Na}$ linguagem metafísica, o termo escrito se torna o signo (escrito) do signo (pronunciado), que remete ao significado original. Nesse ambiente, o texto estabelece suas marcas como sulcos, com possibilidades de ser, no máximo, polissêmico. Enquanto a polissemia promove a proliferação de níveis semânticos e o retorno a si, na direção da plenitude do termo, a disseminação apaga o caminho de volta e a noção de existência de uma matriz de pensamento sobre o conceito em questão (DUQUE-ESTRADA, 2002).

A disseminação não se deixa integrar ao campo simbólico, não se enquadra no conceito tradicional de signo como coisa que se apresenta no lugar de outra, tornando-a compreensível e representando-a. O simulacro talvez seja a característica diferencial da disseminação em relação ao simbólico: configura-se como jogo sem referência a verdades e nem mesmo a mentiras.

Ao abordar textos, dizeres e gestos produzidos e envolvidos em ações de saúde e de educação na saúde, propõe-se a disseminação: opera-se um gesto de explodir sentidos, multiplicando suas possibilidades. Na entrevista a Ėvelyne Grossman, Derrida (2004) trata de seu encanto por Antonin Artaud, quando apresenta a criação experimentada como oco, como vazio. Diz que amava a literatura desde muito jovem, porém evitava escrever, pois carregava consigo a sensação de vazio, como se uma brancura o seguisse. Antes de escrever, não se tem nada a dizer mesmo, pois isso implicaria uma hierarquia entre o autor, o texto e a cena. Ninguém dita nada a Artaud, ninguém lhe sopra o que escrever: seu texto é criação experimentada como véspera do nascimento.

É claro, no entanto, que esta forma de texto inclui riscos e responsabilidades a assumir, e Derrida vincula o desassossego presente nas cartas de Artaud a Rivière com seu pensamento arriscado e revolucionário direcionado, mais tarde, para a criação do teatro da crueldade: os hieróglifos de Artaud são movimentos corporais que não obedecem a um roteiro a priori (DERRIDA, 2004). 
Em disseminação de sentidos de cartas de Artaud, levantam-se planos do real retrátil experimentado por ele: ao tecer vias e desejar a vida mesma na cena, o dramaturgo francês propõe um teatro que se apresenta como crítico das artes clássicas, no que tange à sua intensidade e originalidade. Ao reclamar de seus tratamentos, das sessóes de eletrochoque e do modo como se sente aprisionado, seus dizeres encontram-se com seus leitores, que pouco 'disseminam' os sentidos das condutas estabelecidas, atados que estão às teias do saber científico vigente. Ao dizer desse saber, a estudante A parece conseguir multiplicar seus sentidos, ao notar que há muito mais a saber sobre os modos de viver, adoecer e morrer, em superação de interpretações lineares.

Parece que o encontro com o outro nos processos de atenção e educação tem potencial de criação de práticas singulares e eficazes, à medida que o profissional/ educador/professor da saúde nota a fragilidade dos scripts definidores de suas açôes e perde o interesse na 'vontade de verdade' (MOREIRA, 2007). Muito mais que a busca e o cumprimento de absolutos, as demandas por saúde da população requerem a capacidade de escutar como quem multiplica infinitamente as possibilidades de sentidos e, nesse entre-dois, permitir o surgimento de condutas novas e escolhas partilhadas.

\section{Criar cadeias suplementares}

Um suplemento se configura como "uma adição, um significante disponível que se acrescenta” e fornece um excesso (SANTIAGO, 1976, p. 88). Não complementa, pois não falta. Com Derrida (2005), notamos que, assim como a luz noturna suplementa a luz diurna, a escritura suplementa a fala, sem mediação, sem desvios, sem percursos ocultos (a serem descobertos).

Os paradoxos da suplementaridade são percebidos no texto, como texturas, jogos e nervuras gráficas do vivido. Na transposição dessa lógica para as práticas de atenção e educação, é perceptível que a saúde tem um percurso no qual a doença se inclui, que solicita o cuidado, a terapêutica; as ações coletivas envolvem, por vezes, grandes grupos, sem, contudo, poder massificar a atenção que se quer singular.

Como terapeuta, o profissional de saúde usa os recursos de intervenção clínica, esta referente a kliné (à beira do leito, isto é, inclinado/orientado ao outro), conforme Ceccim (2006) e Cunha (2005); e atua de modo a acrescentar empenho de forças no sentido da vida (que carrega morte) e da saúde (que 
carrega doença), mas não com neutralidade, uma vez que até mesmo a prescrição

não é totalmente inócua. Estes contrários no conceito e na experiência corporal da saúde não se anulam, antes se adicionam, carregam rastros uns dos outros, formando cadeias suplementares.

Numa seção sobre a grande saúde, Nietzsche (2001) a apresenta como um excesso de forças plásticas, que se rearranja em seus triunfos e não lamenta nem evita a dor: "transbordante abundância e potência” (\$ 382, p. 287). Pela lógica do suplemento, a saúde transborda, ao se situar na mesma cadeia de significações que a doença. São contrários que se justapõem, convivem e se suplementam. Não geram terceiros termos nem mesmo promovem consensos.

Ao tomar Artaud por seus excessos, por sua vida-força, sua plenitude, propóese, a partir de leituras dele e sobre ele, em articulação com trechos produzidos pelos estudantes, um gesto de criação de uma cadeia de suplementos.

À rua Barthélemy, 29, Artaud foi matriculado no Internato do Sacré-Cœr, na cidade de Marselha; em 1937, foi internado pela primeira vez em uma instituição psiquiátrica, em uma sequência de mudanças de cidades e instituições por nove anos. Não lhe faltavam elogios quanto à sua inteligência, patrocinados pelos padres da escola. Duas instâncias asilares, que não se complementam, mas se encadeiam. Moradias-modelarias que se mesclam em jogo suplementar de uma sobre a outra. Ciência que se quer produtora de vida, mas que a encerra em confinamentos.

Os surrealistas, como os cientistas, precisavam estar próximos a seus laboratórios, escritórios. Os cafés e cervejarias suplementavam esses espaços, por onde Artaud andava com um turbante negro, com extremidades longas que varriam o chão de Montmartre. Turbantes da boemia parisiense são suplementados pelas camisas de força em Rodez. Nervuras nos quartos coletivos dos asilos. Quartos-escritório de onde tentava controlar seus escritos, publicações, distribuições - em suma, sua arte - através de cartas. Jogo de destinos errantes, o das correspondências e o de Artaud.

As noites inteiras no La Coupole com Blin e a deliciosa festa de família em Marselha no final de 1920. Bares e parentes. Falsa contradição, pois ambos acolhem pela vida inteira; a droga ilícita escondida, levada por um amigo, pois era impossível viver se não estivesse possesso. A droga lícita que o faz dizer que morreu em 1939. A morte-vida de Artaud no manicômio e as suplementares mortes dos que se apresentaram para a guerra declarada em 3 de setembro desse mesmo ano. Instância de suplemento de experiências no mesmo corpo: o corpo do estudante de Medicina, pressionado e achatado por saberes absolutos, os corpos que ele toca e que extrapolam imensamente tudo o que foi assimilado mecanicamente. O corpo de Artaud, que "se debruçava na janela de um vagão e, dizendo adeus a seus pais, reunidos na estação, tirava os sapatos e os batia um contra o outro, sacudindo os últimos vestígios da terra natal" (MĖREDIEU, 2011, p. 127). O teatro da crueldade como o que libera descargas elétricas do corpo, que se desfaz dos órgãos. Inutilidade. Eletrodos dos aparelhos de eletrochoque: vertigem e pesos mortos. 
Cartas agora e sapatos antes; a ampulheta que vira; a poeira que fica. O percurso do trem que levava Artaud de Marselha a Paris. Alegria e dor. Acréscimo e não contradição. Dr. Ferdière de jaleco branco: sentados os dois com as pernas cruzadas no jardim, aguardando a partida de Artaud de Rodez, mais uma vez com destino a Paris. Magro e sério. Os cadernos do retorno a Paris: desenhos, filamentos, fios. Condutos nervosos, rizomas. André Breton, Jean Paulhan, Dr. Ferdière. O teatro Sara Bernhardt. Manuscritos de Simone de Beauvoir. Convívio e isolamento no jogo de loucura e genialidade, de rigor técnico e criatividade.

Artaud parece olhar para Van Gogh e para seu enterro nos trigais, a partir de uma cadeia de elos indiscerníveis: ao suicídio de Van Gogh se sobrepõem as suas próprias relaçôes com médicos-chefes dos asilos de alienados. À água em movimento nas pinceladas e à mística delirante do pintor, Artaud estabelece dobras em gestos e grunhidos no tablado, suplemento de sua infância burguesa nos jardins do terraço da Boulevard de Longchamp número 104.

O pequeno texto apresentado acima, como uma cadeia de suplementos, aponta para uma reflexão acerca dos encontros nas práticas de saúde e para a multiplicidade de nexos e sentidos que podem ser atribuídos ao que tanto a Ciência como o corpo - do paciente, dos grupos, dos estudantes - expressam. As vivências da pessoa atendida e dos coletivos chegam aos profissionais de saúde e este as traduz, a seu modo, para tentar sistematizar e dar conta da demanda; o próprio profissional elabora nexos do que acessa por seus ouvidos, com conceitos científicos, suas vivências, contextos sociais e culturais e o que entende ser necessário ao trabalho e ao outro.

Há uma riqueza quando se assume a impossibilidade da pessoa atendida acessar o significado original do que o médico lhe prescreve; do trabalhador da saúde entender exatamente a dor do outro e o olhar crítico para o fato de docentes e estudantes da saúde se basearem sempre em dogmas científicos. A cadeia de suplementos acima, incluída no exercício de timpanizar, tem a pretensão de provocar processos artísticos, inventivos, criadores, que os encontros nos proporcionam, a partir do reconhecimento de que há aí espaços de criação. Ao tratar do tema da didática e dos processos de tradução de saberes pelo professor, Corazza (2014) aponta para a beleza dos processos educativos que produzem "vita nuova aos originais" (p. 61), desregramentos em relação às imposiçôes do instituído, permitindo invençôes.

Ainda que os enunciados - tanto de Artaud quanto do professor e do aluno - sejam plenos de significaçôes, sempre há a possibilidade de disseminar 
e acrescentar-lhes sentidos. Assim, a dinâmica em saúde permite que os

participantes (usuários, coletivos, docentes, estudantes e profissionais da saúde) ocupem, todos, papel relevante na produção de conhecimento novo, criação de suplementos, invenção de novos nexos teórico-práticos, como arte de fazer.

\section{Considerações finais}

Temas circulantes no campo da Saúde e da Educação na Saúde, quando aparecem em relatos e escrituras de pacientes e de estudantes, são problematizados de modo diferente ao que se vê em prontuários, em entrevistas e em livros de clínica e currículo. Parecem, assim, dizer do que normalmente não se pede, não se indaga. O método de timpanização - como nome dado ao conjunto de procedimentos adotados - parece dar a ver o que normalmente não se indaga e não se nota, justamente por despertar os sentidos e provocar a reflexão despregada do lugarcomum, das ideias-feitas, dos clichês (CORAZZA e AQUINO, 2011).

A discussão desses temas, feita a partir da timpanização derridiana, foi direcionada pela criação de um método em três gestos indissociáveis - tatear escombros, disseminar sentidos e criar cadeias suplementares —, como caminho que favorece o movimento de percepção do inusitado, de aproximação com o vivido, e aponta para o que o corpo sinaliza, mais que para o que os protocolos recomendam.

O tatear escombros parece despertar olhos, ouvidos e mãos para a percepção de aspectos endurecidos do nosso fazer em saúde, já repetidos automaticamente e que não têm mais efeito na saúde das pessoas atendidas; ainda, nos processos educativos - seja com estudantes, seja com pacientes e grupos —, o tatear dos escombros da metafísica faz saltar aos olhos os roteiros previamente estabelecidos e apenas reproduzidos, e o rol de saberes certos que insistimos que devem ser aprendidos, mesmo quando "há muito mais no mundo, na vida e na morte", conforme visto na escrita do estudante.

A disseminação de sentidos é um procedimento de liberdade em relação a esses roteiros, ao script, a significados dados e limitados. Disseminar potencializa os processos de comunicação paciente-profissional, professor-estudante, profissionais entre si, pois abre até o infinito as possibilidades de atribuir sentidos às mesmas coisas. No encontro com os pacientes, a compreensão de seus processos 
de viver, adoecer e morrer fora da perspectiva dualista e com abertura à criação de novos sentidos permite a aproximação em relação à riqueza e às singularidades de suas experiências, bem como de suas possibilidades de aderir aos tratamentos e práticas propostas, não em submissão a recomendações imperativas, mas em movimento de coparticipação no artistar de sua própria vida.

Nesse sentido artistador, a criação de cadeias de suplementos indica que é possível escolher posições a serem ocupadas ante o grande desafio de achar maneiras de favorecer processos de criação em saúde. Diante das opções de base dualista de trabalhar no sentido de normalizar estilos de vida, constituindo rebanhos obedientes e culpabilizados por sua própria condição, generalizando modos de se ter saúde; ou desenvolver um labor medicalizador e hierarquizado, reforçando a dependência em relação a si e ao serviço de saúde, é preciso criar novos elos nessa cadeia de modos de formar e agir em saúde. Acrescentar elementos e abrir espaços parece ser relevante nesse contexto: optar por dar a primazia à singularidade de cada pessoa atendida, no sentido de potencializar a criação da vida e entender que a saúde se apresenta justamente na criação de si.

Em relação à formação na saúde, ao se entender que o Sistema Único de Saúde precisa de profissionais capazes de criar as práticas de saúde, que façam frente aos enquadramentos normativos do campo teórico-prático, torna-se necessário investir numa outra lógica de formação. Se um trabalhador da saúde não deve agir no sentido de formar rebanhos de pacientes, é preciso que seu percurso formativo aconteça fora do cativeiro. A aula na qual foram produzidos os textos parece ter buscado esse modo de ensinar e aprender, com abertura à sensibilização e à participação do estudante na produção de conceitos novos.

O método de timpanização se apresenta como via de pensamento que impulsiona a desnaturalização desses modos de ver e fazer problematizados aqui, a partir da luxação dos ouvidos para a escuta crítica de tons dualistas que percorrem as práticas de saúde e educação na saúde. A aproximação com alguns tópicos do pensamento de Jacques Derrida, em abordagens pouco usuais nas discussōes sobre práticas de saúde, pode servir de provocação ao pensamento e surgimento de outras pesquisas com este referencial. Nota-se um potencial de ampliação da problemática das práticas e das experiências em saúde: de produção de conhecimento, de pensar, formar e pesquisar na Saúde. ${ }^{1}$ 


\section{Referências}

ARTAUD, A.. Cartas desde Rodez, II. Trad. Ramón Font. Madrid: Fundamentos, 1986.

AZEREDO, V.D. de; SILVA JÚNIOR, I. Nietzsche e a interpretação. São Paulo: Humanitas; Curitiba: CRV, 2012.

BARTHES, R.. A preparação do romance I: da vida à obra. Notas do curso no Collège de France 1978-1979. Trad. Leyla Perrone-Moysés. São Paulo: Martins Fontes, 2005.

BEDWORTH, D.; BEDWORTH, A. Dictionary of health education. New York: Oxford University Press, 2009.

BIATO, E.C.L.; MONTEIRO, S.B. Timpanização de Escrileituras. Vias marginais para os objetos duplos. In: CORAZZA, S.; ADÓ, M.; OLINI, P. Caderno de notas 9: Panorama de pesquisa em Escrileituras: Observatório da Educação. Porto Alegre: UFGRS: Doisa, 2016, p. 178-189.

ONOCKO-CAMPOS, R.O.; CAMPOS, G.W. A co-construção da autonomia. In: CAMPOS, G.W. et. al. (Orgs.). Tratado de saúde coletiva. 3. ed. São Paulo: Hucitec; Rio de Janeiro: Fiocruz, 2006, p. 669-688.

CAPUTO, J. Por amor às coisas mesmas: o hiper-realismo de Derrida. In: DUQUEESTRADA, P.C. Às margens: a propósito de Derrida. Rio de Janeiro: PUC-Rio; São Paulo: Loyola, 2002, p. 29-48.

CECCIM, R.B. Réplica. Interface - Comunicação, Saúde, Educação. Botucatu, v. 9, n. 16, p. 161-177, 2005.

. Equipe de saúde: perspectiva entre-disciplinar na produção dos atos terapêuticos. In: PINHEIRO, R.; MATTOS, R.A. (Orgs.). Cuidado: as fronteiras da integralidade. 3. ed. Rio de Janeiro: IMS/Uerj; São Paulo: Abrasco, 2006, p. 259-78.

CORAZZA, S.M.; AQUINO, JG. Dicionário das ideias feitas em educação. Belo Horizonte: Autêntica, 2011.

CORAZZA, S.M. Didattica da tradução. In: SCHULER, B.; MATOS, S.R.; CORAZZA, S.M. Caderno de notas 6: experimentações de escrita, leitura e imagem na escola. Porto Alegre: UFRGS: Doisa, 2014, p. 47-64.

COSTA, L.B. Biografema como estratégia biográfica: escrever uma vida com Nietzsche, Deleuze, Barthes e Henry Miller. 2010. Tese (Doutorado em Educação) - Universidade Federal do Rio Grande do Sul, Programa de Pós-Graduação em Educação. Porto Alegre, RS, 2010.

CUNHA, G.T. A construção da clínica ampliada na atenção básica. São Paulo: Hucitec, 2005. DERRIDA, J. Margens da filosofia. Trad. Joaquim Torres Costa e António M. Magalhães. Campinas-SP: Papirus, 1991.

. As vozes de Artaud. Entrevista com Ėvelyne Grossman. Magazine littéraire, n. 434, 2004. (Edición digital de Derrida em Castellano). 

. Posiçôes. Trad. Tomaz Tadeu da Silva. Belo Horizonte: Autêntica, 2001. . A farmácia de Platão. Trad. Rogério da Costa. São Paulo: Iluminuras, 2005. - A escritura e a diferença. Trad. Maria Beatriz Marques Nizza da Silva, Pedro Leite Lopes e Pérola de Carvalho. 4. ed. São Paulo: Perspectiva, 2009a. (Estudos 271, dirigida por J. Guinsburg).

. Otobiografías. La enseñanza de Nietzsche y la política del nombre propio. Buenos Aires: Amorrortu, 2009b.

DUQUE-ESTRADA, P.C. Derrida e a escritura. In: DUQUE-ESTRADA, P.C. Às margens: a propósito de Derrida. Rio de Janeiro: PUC-Rio; São Paulo: Loyola, 2002, p. 9-28.

LÉBRUN, G. Para que ler Nietzsche, hoje? In: LÉBRUN, G. Passeios ao léu. São Paulo: Brasiliense, 1983, p. 32-40.

LUCY, N. A Derrida dictionary. Hobokey, New Jersey: Blackwell publishing, 2004.

MARTON, S. Nietzsche. eBook, 2013. ISBN: 9788516076672.

MÈREDIEU, F. Eis Antonin Artaud. Trad. Isa Kopelman e equipe Perspectiva. São Paulo: Perspectiva, 2011.

MEYER, D.E.; PARAÍSO, M.A. Metodologias de pesquisas pós-criticas em educação. Belo Horizonte: Mazza Edições, 2012.

MONTEIRO, S.B.; BIATO, E.C.L. Uma avaliação crítica acerca de método e suas noções. Revista de educação pública, v. 17, n. 34, p. 255-271, 2008.

MONTEIRO, S.B.; BIATO, E.C.L.; MORAES, M.A.; SILVA JR. A.J. Possibilidades investigativas em educação e saúde. In: SILVA, M. das G.; PEREIRA, W.R. Educação e saúde: confluências de conhecimentos e vivências. Cuiabá: EdUFMT, 2012, p. 297-315.

MOREIRA, A.B. Nietzsche e o cinismo grego: elementos para a crítica à "vontade de verdade”. Cadernos Nietzsche. São Paulo, 22, 2007.

NIETZSCHE, F.W. A gaia ciência. Trad., notas e posfácio de Paulo César de Souza. São Paulo: Companhia das Letras, 2001.

. Aurora. Trad. Paulo César de Souza. São Paulo: Companhia das Letras, $2004 a$.

_____. Fragmentos do espólio. Julho de 1882 a inverno de 1883/1884. Brasília: Editora $\mathrm{UnB}, 2004 \mathrm{~b}$.

- Crepuísculo dos idolos. Trad. Paulo César de Souza. São Paulo: Companhia das Letras, 2006.

. Fragmentos póstumos. Disponível em: <www.nietzschesource.org>. Acesso em: fevereiro de 2012.

PEETERS, B. Derrida. Trad. André Telles. Rio de Janeiro: Civilização Brasileira, 2013.

PORTER, R. História da Medicina. Rio de Janeiro: REVINTER, 2008. 
SANTIAGO, S. Glossário de Derrida. Rio de Janeiro: Livraria Francisco Alves Editora, 1976.

SIGERIST, H.E. Civilização e doença. São Paulo: Hucitec: Sobravime; Campinas: SindiMed, 2011.

\section{Agradecimentos}

À Fapemat, pelo financiamento de projeto de pesquisa do qual alguns dados aqui apresentados são resultantes. E ao Observatório da Educação CAPES/INEP, pelo financiamento de parte deste estudo.

\section{Nota}

${ }^{1}$ E.C.L. Biato propôs a escrita inicial e as ideias para o artigo. R.B. Ceccim participou de discussões e da redação final do texto. S.B. Monteiro participou de discussões conceituais e revisou o artigo. 


\section{Creation processes in health and health education: a "tympanizing" exercise} The study proposes reflections about care practices and health education. These practices, in many respects, are permeated by a dualistic base, which weakens the educational power and effectiveness in health promotion. There is the hypothesis that the tympanizing gesture proposed by Jacques Derrida, offers a possibility of a methodological approach to the subject, exercise that is done through an Antonin Artaud's letter, considering his biography and his health and illness experiences. Tympanizing includes three procedures: groping the wreckage; disseminating meanings and invention of supplements chains. This method can open different meanings for knowledge and practices of attention and health education.

> Keywords: philosophy; method; health education; healthphilosophy-education triad; teaching health. 